NBER WORKING PAPER SERIES

\title{
THE CREATION OF THE RULE OF LAW \\ AND THE LEGITIMACY OF PROPERTY RIGHTS: THE POLITICAL AND ECONOMIC CONSEQUENCES OF A CORRUPT PRIVATIZATION
}

\author{
Karla Hoff \\ Joseph E. Stiglitz \\ Working Paper 11772 \\ http://www.nber.org/papers/w11772 \\ NATIONAL BUREAU OF ECONOMIC RESEARCH \\ 1050 Massachusetts Avenue \\ Cambridge, MA 02138 \\ November 2005
}

Hoff: World Bank, Washington DC 20433; Stiglitz: Columbia University, New York, NY 10027. We thank Mayuresh Kshetramade for outstanding research assistance. We benefited from valuable suggestions from Avinash Dixit, Branko Milanovic, the editor Andrew Scott, Ken Sokoloff, two anonymous referees, and seminar participants at Berkeley, Harvard's center for Political Institutions and Economic Policy (PIEP), Pennsylvania State University, Princeton, UCLA, the World Bank, and meetings of the American Political Science Association. Hoff thanks the MacArthur Research Network on Inequality and Economic Performance for financial support. The findings and interpretations expressed in this paper are those of the authors and do not necessarily represent the views of the World Bank. The views expressed herein are those of the author(s) and do not necessarily reflect the views of the National Bureau of Economic Research.

(C2005 by Karla Hoff and Joseph E. Stiglitz. All rights reserved. Short sections of text, not to exceed two paragraphs, may be quoted without explicit permission provided that full credit, including (C notice, is given to the source. 
The Creation of the Rule of Law and the Legitimacy of Property Rights: The Political and Economic Consequences of a Corrupt Privatization

Karla Hoff and Joseph E. Stiglitz

NBER Working Paper No. 11772

November 2005

JEL No. K0, K4, P26

\title{
ABSTRACT
}

How does the lack of legitimacy of property rights affect the dynamics of the creation of the rule of law? We investigate the demand for the rule of law in post-Communist economies after privatization under the assumption that theft is possible, that those who have "stolen" assets cannot be fully protected under a change in the legal regime towards rule of law, and that the number of agents with control rights over assets is large. We show that a demand for broadly beneficial legal reform may not emerge because the expectation of weak legal institutions increases the expected relative return to stripping assets, and strippers may gain from a weak and corrupt state. The outcome can be inefficient even from the narrow perspective of the asset-strippers.

\author{
Karla Hoff \\ Room MC3-367 \\ World Bank \\ 1818 H Street \\ Washington, DC 20433 \\ khoff@worldbank.org \\ Joseph E. Stiglitz \\ Uris Hall, Columbia University \\ 3022 Broadway, Room 814 \\ New York, NY 10027 \\ and NBER \\ jes322@columbia.edu
}


The central issue in this paper are the dynamics of transition to the rule of law-an issue that has become paramount in the debate over the transition from communism to a market economy. There is a long history recognizing that property rights are very important. There has also been a long debate about how the institutions of property rights evolved (e.g., Smith, 1776, Book III, iv; Marx and Engels, 1848; North 1981). In Western European history, in general, they evolved gradually and incrementally. But for transition and developing countries today, policymakers seek to expedite this process. For the countries in transition from communism, the theory was put forward that the process could be expedited by the mass privatization of state enterprises to individuals: Privatization would create a demand for property rights institutions and the rule of law. ${ }^{1}$ The institutional evolution that was expected to follow would lead to growth-wealth creation and wealth maximization. There was a logic to this theory, but the theory neglected a variety of reasons why rapid privatization might not have the desired effect on institutional change.

Preliminary evidence more than a decade out is that this strategy has not worked in Russia and many other transition countries. The political scientist Stephen Holmes (2002, p. 87) writes that "no well-organized constituency for the rule of law exists in Russia today" and that for lack of one, the rule of law cannot be established. This view is shared by numerous scholars with respect to not only Russia but also many other

\footnotetext{
${ }^{1}$ For example, Shleifer and Vishny (1998) argued that "Privatization offers an enormous political benefit for the creation of institutions supporting private property because it creates the very private owners who then begin lobbying the government...to create market-supporting institutions ... [Such] institutions would follow private property rather than the other way around" (pp. 10-11). Privatization creates "an economically and politically powerful lobby for institutional reform” (Boycko, Shleifer, and Vishny, 1995 , p. 154), central to which is the rule of law (Hay, Shleifer, and Vishny 1996, p. 96).
} 
transition countries. ${ }^{2}$ Figure 1 plots nonparametric estimates of the distribution, in 1996 and 2004, of World Bank scores of adherence to the rule of law for 27 transition countries and the world as a whole. ${ }^{3}$ The rule of law indicator is scaled so that the values of the world average and median are zero and the standard deviation is one. Higher scores represent greater adherence to the rule of law. In 1996, the transition countries had, on average, slightly less adherence to the rule of law than the world as a whole, but showed a low level of dispersion. Between 1996 and 2004, a twin peaks pattern emerged in the transition countries: Some achieved a good measure of rule of law by world standards, while the majority had scores that remained low or even deteriorated. When it became clear in Russia's privatization that many individuals were obtaining equity stakes through rigged bids and that controlling shareholders were stripping assets, even then some people argued that businessmen would, sooner or later, settle down to value-building. The following passage attributed in 1996 to the first head of Russia's privatization program (Anatoly Chubais) is suggestive:

\footnotetext{
${ }^{2}$ See, for example, Pistor (1999) and the symposium "Demand for Law" in the East European Constitutional Review, Hellman (1998, 2002), Aslund and Dmitriev (1999), Black et al. (2000), Nagy (2000, p. 88), Sperling (2000, pp. 16-17), Kolodko (2001), and Graham (2002, esp. p. 49). Other scholars have argued that in many countries, the cause of the absence of the rule of law lies on the supply side-for instance, the inability to collect taxes to finance a market-oriented system (Johnson, Kaufmann, and Shleifer (1997) and Roland and Verdier (1999)). But financial problems reflect endogenous decisions of essentially the same kind as the demand side that we analyze here. In Russia, it was clear that the state was giving away assets of value an order of magnitude greater than the cost of administering a rule of law system. The lack of finance was a reflection of the same lack of demand for the rule of law on which we focus here.

${ }^{3}$ The governance indicators are weighted composite scores constructed by Kaufmann, Kraay, and Mastruzzi (2005) from indicators produced by 31 organizations, including Freedom House and the European Bank for Reconstruction and Development.
} 
"They steal and steal and steal," Chubais complained of the country's businessmen and their routinely corrupt practices. "They are stealing absolutely everything and it is impossible to stop them. But let them steal and take their property. They will then become owners and decent administrators of this property." (Freeland, 2000, p. 70)

But there was no way to evaluate how long that would take, or what price would be paid in the interim. Many apologists for what was happening in Russia suggested that the theft was nothing more than redistribution—a small price to pay for establishing the rule of law and thereby attaining an efficient economy. In contrast, in this paper, we present a model in which there are social costs attendant to theft.

We argue that the linkage between privatization and the demand for the rule of law has been misinterpreted. A central analytical failure is misunderstanding the difference between an individual's owning an asset and an individual's having control over an organization of which he is not the sole owner. ${ }^{4}$ Control rights enable one to take others' assets. In the absence of the rule of law, control rights undermine more general property rights because they make it easy to steal. Privatization without institutions to enforce good corporate governance may vitiate private property rights and give those with control rights an interest in the persistence of a weak, corrupt state that would not interfere with their theft.

The paper is organized as follows. In Section 1, we present an infinite period

\footnotetext{
${ }^{4}$ The mass privatization in Russia in the early 1990s entailed the transfer of control rights before the establishment of rules of corporate governance and other institutions to limit the abuse of corporate control. If it is expected that one person would quickly get control of all the assets of the entire corporation, then that person will simply want to be sure that no one steals from him. So there is a model of a world of vast inequality in which issues of corporate governance are of only fleeting concern. In the 1990s, no one openly contemplated that degree of inequality and had they done so, concerns about equality might have motivated attempts to limit such concentrations of economic power.
} 
model in which forward-looking agents who control assets choose an economic strategyto build value or strip assets—and express in each period, e.g., by voting, a political preference for or against establishing the rule of law. The probability of transition to the rule of law depends on the size of the constituency that demands it, and an agent's optimal economic strategy depends on his beliefs about when the transition to the rule of law will occur. If he believes that this constituency is large, so that the probability of transition is high, then the relative expected returns to building value and to supporting the rule of law will both be high. This is the scenario predicted by supporters of rapid privatization. If, however, the agent believes that the constituency for the rule of law is small, then the expected return to building value (relative to stripping assets) will be low and he may choose to strip assets. Asset stripping may in turn give him a preference for postponing the establishment of the rule of law because stripping gives him a stake in the existing system that does not interfere with his theft. We assume that the individual votes his self-interest. This means that he compares the long-run gain from a more efficient society under the rule of law to his short-run foregone ability to strip. He naturally ignores any effect of his behavior on how others invest and vote. We show that even if only those who have control rights determine the outcome of the political process (i.e., those who under the naïve theory would support the rule of law), the outcome of the interactions of many actors may be very inefficient because the political environment is a public good (or public bad). We show that a weak constituency for the rule of law may be self-perpetuating.

In Section 2, we solve the model for a numerical example and illustrate the stark implications that the mechanism studied in the paper can have for growth. Economists are well attuned to analyzing group behavior that is inconsistent with what would be in 
the interests of each and all if they could act cooperatively. We provide a setting of interactions between economic and political decisions that illustrates this failure dramatically. We thus show that the argument that mass privatization always leads to a demand for a wealth-maximizing legal regime is not correct. ${ }^{5}$

In Sections 3 and 4, we consider the assumptions of our model in more detail and use the model to address three policy questions One concerns the sequencing of privatization of large state enterprises and regulation of corporate governance. We show that whether or not privatization first, as rapidly as possible, is superior to the strategy of regulation of corporate governance first depends on the magnitude of certain behavioral parameters. As a second example, we consider macroeconomic stabilization policy to address the inflation that accompanied price decontrol. We ask: what is the effect of high interest rates on the size of the constituency for the rule of law? We show that at high interest rates, the relative returns to stripping assets and opposing the establishment of the rule of law may both rise; thus, a too stringent macroeconomic policy can undermine the constituency for legal reform. As a third example, we consider the liberalization of international capital flows. When capital flight is easier, the relative return to stripping assets will rise and the constituency for the rule of law will fall.

In the concluding section of the paper, we consider the problem highlighted in our

\footnotetext{
${ }^{5}$ A key issue that this paper does not deal with is oligarchy. The reason that we begin with the model of this paper is that it is obvious that the creation of oligarchs would lead to a demand to preserve the differential access to power, as opposed to the rule of law. This paper will show that the problem with the strategy of using mass privatization to jumpstart institutional change is not just, nor even, the creation of the oligarchs, but the broader problem of corporate governance and the social consequences of widespread asset stripping. This problem can arise in the absence of concentrated wealth, and concentrated wealth exacerbates the problem we identify here—see Figure 9.
} 
model in a broader context. The issue is how, when the legitimacy of the distribution of property rights is contested, a society can establish a foundation for building the rule of law. The various forms that privatization took represented alternative ways of assigning private property rights at the beginning of the transition from communism. The question of the assignment (origins) of property rights and their legitimacy has bedeviled many African countries, as well. We argue that the Coasian view that focuses on the problem of defining property rights, rather than the broader problem of building a political consensus for rules that will govern their allocation, is a misleading guide to building a political constituency for the rule of law and an efficient economy.

\section{A dynamic model of the demand for the rule of law}

In this section we develop our basic model of the demand for the rule of law.

\subsection{The agents}

A continuum one of agents has control rights over enterprises. We think of time as divided into an infinite number of periods, in each of which the agents choose between two actions:

Building value: Making an irreversible investment to increase the enterprise's value.

Stripping assets: Stripping the assets of the enterprise, appropriating corporate value for themselves, whisking capital to a safe place, and letting the capital stock wear out.

All agents have identical preferences, with a discount factor $\delta \in(0,1)$, but agents differ in their ability to strip assets. For instance, those who control natural resources that can be extracted and sold on world markets in a process relatively insulated from the rest of the economy have the greatest ability to strip assets. $\theta$ denotes an agent's type. Agents with a higher value of $\theta$ strip better. We assume that $\theta$ has a continuous distribution $H(\theta)$ and density function $h($.$) .$ 


\subsection{The political environment}

We consider a society in which the possible legal structures vary only along the dimension of the security of property rights. The two possible legal structures in our model capture the ends of the spectrum. By the rule of law, we mean well-defined and enforced property rights, broad access to those rights, and predictable rules, uniformly enforced, for resolving property rights disputes. By no rule of law, we mean a legal regime that does not protect minority shareholders' rights from tunneling, does not enforce contract rights, and does not protect investors' returns from confiscation by the state. We will refer to these two legal regimes as states of the world. We assume that initially the economy is in the non-rule-of-law state. ${ }^{6}$

In each period, agents have to express a political preference, e.g., by voting over policies that would create the rule of law. A fraction of the agents, denoted by $1-x_{t}$, demand the rule of law, while the remainder $\left(x_{t}\right)$ oppose its establishment. These political preferences determine the probability of transition to the rule of law at the end of that period. ${ }^{7}$ Thus, we assume that the probability, $\pi_{t}$, of transition to the rule of law in period $t$ is a decreasing function of $x_{t}$ :

$$
\pi_{t}=\pi\left(x_{t}\right), \quad \pi^{\prime}(.)<0 \text { for } x \in(0,1), \quad 0=\pi(1)<\pi(0)=1 .
$$

\footnotetext{
${ }^{6}$ To illustrate, we cite four characterizations of the environment in Russia in which mass privatization occurred: "a wild market outside the law" (Rose 1993, p. 430), a "systemic vacuum...[without] effective regulations and controls" (Kolodko 2000, p. 196); "a lawless climate, in which managers could justify selfdealing by claiming (sometimes correctly) that they had done nothing illegal" (Black et al. 2000, p. 1782); "a robber-anarchical form of capitalism" (Nagy 2000, p. ix).

${ }^{7}$ A part of the economy does not have assets. A premise of the analysis is that those who do are the decisive players.
} 
Once a society attains the rule of law, we assume that it continues in that state forever. ${ }^{8}$ Similar results would hold if there were a small probability of reversion to the non-ruleof-law state.

We will explore a subset of possible equilibrium paths such that, as long as no rule of law prevails, the fraction of agents opposed to reform remains the same: $x_{t}=x_{t+1}=x_{t+2}=\ldots$. There are other dynamics where the constituency may jump from one period to the next, which we do not explore.

\subsection{The payoffs}

Technology is constant returns to scale. If an individual builds value in a given period, he obtains an income flow $f$ per unit asset and increases the asset to a proportion $\tilde{g}>1$ of its former size. We assume $\delta \tilde{g}<1$ so that asset values are finite.

To build value requires an investment $I^{j}<f$ per unit asset. $I^{j}$ depends on the state of the world at the end of the period, indexed by $j: j$ is rule of law $(L)$ or no rule of law $(N)$. We assume $I^{L}<I^{N}$, which captures the idea that in order to build value an individual must interact with others. He benefits from the rule of law because it enforces his property rights and expands his access to markets. Without the rule of law, he risks even being able to capture the return on his investment in productive assets. ${ }^{9}$ Let $b^{j}$ denote the net flow per unit asset to an agent who builds value:

\footnotetext{
${ }^{8}$ This assumption follows naturally from the central case considered in this paper, namely, that the rule of law is the Pareto optimal state—see (6). Weingast (1997) formalizes this idea.

${ }^{9}$ For simplicity, we have modeled the technology as requiring a given level of investment so that, in the absence of the rule of law, higher levels of investment are needed, e.g. to obtain inputs and protect assets. Alternatively, we could have modeled the rule of law as entailing an increased return from the same level of investment. Nothing depends on the simplification chosen.
} 


$$
b^{j}=f-I^{j} \quad \text { for } j=L, N
$$

The model makes an important simplification that leads to an underestimate of the value of the rule of law: it abstracts from externalities that affect $f$ and $\tilde{g}$. In reality, if a large fraction of the economy is engaged in asset stripping, then (as in Russia in the 1990s) overall production will suffer and $f$ and, most importantly, $\widetilde{g}$ will be depressed. ${ }^{10}$

Next consider the payoffs to stripping assets. An agent who strips may increase the current income per unit asset at the cost of reducing the asset to a proportion $\tilde{z}<1$ of its former size. An agent of type $\theta$ can only strip so much, and the rule of law further constrains his ability to strip. Let $s^{j}$ denote the flow per unit asset to an agent who strips:

$$
s^{N}(\theta)=\theta, \quad s^{L}(\theta ; \lambda)=\theta[1-\lambda] \quad \text { with } \lambda>0 .
$$

$\lambda$ represents the diminution in the ability to strip after the imposition of the rule of law. $\lambda>0$ means that the rule of law circumscribes certain actions used by strippers to maximize their returns. In effect, the way we model it, $\lambda$ measures the reappropriation by the state of assets that have been illegitimately appropriated.

To simplify notation, let

$$
g \equiv \delta \tilde{g} \text { and } z \equiv \delta \tilde{z}
$$

and let $V^{j}$ denote the present discounted value of future lifetime income per unit asset if the initial state is $j$. Thus,

\footnotetext{
${ }^{10}$ In particular, the return to asset stripping will be increased relative to that of building value. There are other channels besides the impact on aggregate demand. With lower levels of production, the demand for non-traded intermediate goods is reduced, and this has adverse effects on aggregate supply. If many people are engaged in corruption, the relative returns to being honest may fall. These kinds of direct interdependencies among economic agents, which we abstract from here, are the focus of Murphy, Shleifer, and Vishny (1993) and Acemoglu (1995).
} 


$$
V^{L}=\frac{b^{L}}{1-g}
$$

In this section, we assume building value under the rule of law yields every agent (weakly) higher lifetime income than stripping assets under no rule of law:

$$
V^{L} \geq \frac{\theta}{1-z} \text { for all } \theta \text { and } V^{L}>\frac{\theta}{1-z} \text { for some } \theta
$$

which implies that the rule of law is the Pareto optimal regime. Writing (6) as an equality fixes the maximum upper bound of $\theta$ in the population, denoted $\theta_{\max }$ : that is, $V^{L}=\frac{\theta_{\max }}{1-z}$. It is interesting to consider the case where (6) holds because we can show that, even in this case, a large fraction of agents may oppose the establishment of the rule of law along the equilibrium path from state $N$ to state $L$.

Circumstances under which (6) would not hold are sufficient access to power by some agents, which would confer sufficiently large opportunities to extract rents through self-dealing, that the agents would always prefer the non-rule-of-law state. We will illustrate such a case at Figure 9 and show that it amplifies the coordination problem on which we focus here. ${ }^{11}$

\subsection{The agent's economic strategy}

This completes the set-up and we proceed to the analysis. We first consider an agent's economic strategy starting from state $N$. Then we consider each agent's political behavior and the interaction of economics and politics.

\footnotetext{
${ }^{11}$ Another circumstance under which the assumption in (6) would not hold is rampant greed by government. Suppose the rule of law is accompanied by a tax rate $t^{L}$. Then $b^{L}-b^{N}=I^{N}-I^{L}-t^{L} f$ can be of either sign. We owe this point to Avinash Dixit.
} 
Individual choice in state $N$ to strip assets or build value is predicated on aggregate political behavior $(x)$. Each agent has an expectation concerning $x$ and in the equilibria explored here, this expectation is correct. For a given value of $x$, expected income to an agent of type $\theta$ is $\bar{b}(x)=\pi(x) b^{L}+[1-\pi(x)] b^{N}$ if he builds value, and $\bar{s}(x, \theta ; \lambda)=\theta[1-\pi(x) \lambda]$ if he strips assets. We can characterize an individual's decision problem by writing the appropriate Bellman equation. For an agent of type $\theta$, let $W(x, \theta ; \lambda)$ denote the optimal value function, ${ }^{12}$ so

$$
W(x, \theta ; \lambda)=\frac{\max \left\{\bar{b}(x)+g\left[\pi(x) V^{L}+[1-\pi(x)] W(x, \theta ; \lambda)\right],\right.}{\left.\bar{s}(x, \theta ; \lambda)+z\left[\pi(x) V^{L}+[1-\pi(x)] W(x, \theta ; \lambda)\right]\right\} .}
$$

For building value in state $N$ to be the optimal strategy, we need

$$
\begin{aligned}
W(x, \theta ; \lambda) & =\bar{b}(x)+g\left[\pi(x) V^{L}+[1-\pi(x)] W(x, \theta ; \lambda)\right] \\
& \geq \bar{s}(x, \theta ; \lambda)+z\left[\pi(x) V^{L}+[1-\pi(x)] W(x, \theta ; \lambda)\right],
\end{aligned}
$$

which implies ${ }^{13}$

$$
\{1-z[1-\pi(x)]\} \bar{b}(x)-\{1-g[1-\pi(x)]\} \bar{s}(x, \theta ; \lambda)+\pi(x)[g-z] V^{L} \equiv \Delta(x, \theta ; \lambda) \geq 0
$$

(10) defines a function $\Delta(x, \theta ; \lambda)$ that has the same sign as the lifetime expected gain from building value in state $N$ rather than stripping assets. The inequality in (10) is satisfied if the expected current income loss, if any (the difference between the first two terms), is offset by the expected lifetime gain after transition to the rule of law (the third

\footnotetext{
${ }^{12} \lambda$ is the only system-level parameter that will vary in our analysis.

${ }^{13}$ In computing (10), we use (8) to solve for $W(x, \theta ; \lambda)$ and substitute this value into (9).
} 
term, which is positive since $g>z$ ).

A similar analysis can be carried out for stripping assets in state $N$ to be optimal. By reversing the inequality in (8) and (9), the condition simplifies to (10) except with the inequality reversed.

Since $\Delta$ is decreasing in the agent's ability to strip, that is,

$$
\frac{\partial \Delta(\theta, x ; \lambda)}{\partial \theta}=-[1-\pi(x) \lambda][1-g(1-\pi(x))]<0
$$

there is a critical value, $\theta_{a}$, where $\Delta(\theta, x ; \lambda)=0$. The critical type, $\theta_{a}(x ; \lambda)$, is implicitly defined by the economic switch line: $V^{N}(x)-S^{N}(x, \theta ; \lambda)=0$ or, more compactly,

$$
\Delta\left(x, \theta_{a} ; \lambda\right) \equiv 0
$$

\section{Economic switch line}

Agents with $\theta \leq \theta_{a}(x ; \lambda)$ build value in state $N$ and have future lifetime expected income $V^{N}(x)=\bar{b}+g\left\{\pi(x) V^{L}+[1-\pi(x)] V^{N}(x)\right\}$ or, equivalently,

$$
V^{N}(x)=\frac{\bar{b}+\pi g \frac{b^{L}}{1-g}}{1-g[1-\pi]}=\frac{\bar{b}}{1-g}+\frac{\pi g}{1-g}\left[V^{L}-V^{N}(x)\right] .
$$

Agents with $\theta>\theta_{a}$ strip assets in state $N$ and have future lifetime expected income $S^{N}(x, \theta ; \lambda)=\bar{s}+z\left\{\pi(x) V^{L}+[1-\pi(x)] S^{N}(x, \theta ; \lambda)\right\}$ or, equivalently,

$$
S^{N}(x, \theta ; \lambda)=\frac{\bar{s}+\pi z \frac{b^{L}}{1-g}}{1-z[1-\pi]}=\frac{\bar{s}}{1-z}+\frac{\pi z}{1-z}\left[V^{L}-S^{N}(x, \theta ; \lambda)\right]
$$

The bracketed terms on the far right-hand side of (13) and (14) are the capital gains from 
transition to the rule of law. (Given (6), this is a gain.)

An increase in $x$, by reducing the probability of transition to the rule of law,

lowers the expected income from building value $(\bar{b})$ and raises the expected income from asst stripping $(\bar{s})$. Both effects lower the economic switch point in state $N$. Thus, the economic switch line is a downward sloping function of $x$-see Figure 2. Proposition 1 states this and also the intuitive result that greater constraints on stripping under the rule of law shift up the economic switch line.

Proposition 1. (a) $\frac{\partial \theta_{a}(x ; \lambda)}{\partial x}<0$ and $\quad$ (b) $\frac{\partial \theta_{a}(x ; \lambda)}{\partial \lambda}>0$.

Proof. (a) Differentiating (12) gives $\frac{\partial \theta_{a}}{\partial x}=-\pi^{\prime} \frac{\partial \Delta\left(x, \theta_{a} ; \lambda\right) / \partial \pi}{\partial \Delta\left(x, \theta_{a} ; \lambda\right) / \partial \theta}$, where

$$
\frac{\partial \Delta\left(x, \theta_{a} ; \lambda\right)}{\partial \pi}=\left[b^{L}-b^{N}\right]\{1-[1-\pi] z\}+\theta_{a} \lambda\{1-[1-\pi] g\}+\left\{[g-z] V^{L}-g \bar{s}\left(x, \theta_{a} ; \lambda\right)+z \bar{b}(x)\right\}
$$

The first two terms of (15) are positive by construction, and we prove in the Appendix that the final bracketed term is positive. Part (a) then follows immediately from (11). The more sensitive the relative return $\Delta($.$) is to aggregate political behavior x$, the steeper the switch line will be.

(b) Similarly we obtain $\frac{\partial \theta_{a}}{\partial \lambda}=-\frac{\pi(x) \theta_{a}[1-g[1-\pi(x)]]}{\partial \Delta\left(x, \theta_{a} ; \lambda\right) / \partial \theta}>0$, by using (11).

\subsection{The agent's political position}

In each period, agents have to express a political preference, e.g., by voting. In state $L$, all agents build value and support the rule of law (given (6)), so we have only to analyze 
the agent's political position in state $N$. Those who build value will demand the rule of law, since they earn higher returns under the rule of law. But asset-strippers face a tradeoff: their lifetime payoff is $\theta-\lambda \theta+z V^{L}$ if the transition to the rule of law occurs in the current period, and $\theta+z S^{N}(x, \theta ; \lambda)$ otherwise. Let $\beta$ denote an asset-stripper's benefit (which could be positive or negative) from prolonging the non-rule-of-law state: ${ }^{14}$

$$
\beta(x, \theta ; \lambda)=\lambda \theta-z\left[V^{L}-S^{N}(x, \theta ; \lambda)\right] .
$$

The two terms on the right-hand side are the gain in current income and the capital loss on the reduced asset base.

$\beta$ is monotonically increasing in the ability to strip, i.e.,

$$
\frac{\partial \beta}{\partial \theta}=\lambda+\frac{z[1-\pi \lambda]}{1-z[1-\pi]}>0
$$

and so there exists a critical value $\theta_{p}$ where $\beta=0$. When $\theta>\theta_{p} \geq \theta_{a}$, an individual will strip assets and oppose the transition to the rule of law. When $\theta \in\left(\theta_{a}, \theta_{p}\right)$, an individual will strip assets but demand the rule of law. The critical value $\theta_{p}$ solves

$$
\beta\left(x, \theta_{p} ; \lambda\right) \equiv 0
$$

As intuition would suggest, the benefit to an asset stripper from prolonging the non-ruleof-law state is larger, the more that the state reappropriates of his gains that have been illegitimately appropriated:

$$
\frac{\partial \beta}{\partial \lambda}=\frac{1-z}{1-z[1-\pi]} \theta>0 .
$$

\footnotetext{
${ }^{14}$ We treat (16) as if it were defined over all $\theta$, but it affects behavior only through (22) (depicted in Figure 2), and thus only for types with $\theta>\theta_{a}$, i.e., only for asset strippers.
} 
Note also that for a type who has a stake in the existing system that does not interfere with his theft (i.e., a type for whom $\beta(x, \theta ; \lambda)>0$ ), an increase in the opposition to the rule of law $(x)$ increases $\beta$. In contrast, for a type who is hurt by the absence of the rule of law, an increase in $x$ reduces $\beta$. What is important to our analysis is only the knife-edge case $\beta(x, \theta ; \lambda)=0$. Intuitively, an agent who is indifferent between states $N$ and $L$ will also be indifferent to the size of the constituency against reform. Formally we have:

$$
\frac{\partial \beta}{\partial x}=z \frac{\partial S^{N}}{\partial \pi} \pi^{\prime}=\frac{-z \pi^{\prime} \beta(x, \theta ; \lambda)}{1-z[1-\pi]} \frac{\rangle}{<} 0 \text { as } \beta \frac{\rangle}{<} 0 .
$$

The next result follows immediately from these properties.

Proposition 2. $\theta_{p}(x ; \lambda)$ is decreasing in $\lambda$ and invariant to aggregate political behavior $(x)$.

$$
\frac{\partial \theta_{p}}{\partial \lambda}=-\frac{\partial \beta / \partial \lambda}{\partial \beta / \partial \theta}<0, \quad \frac{\partial \theta_{p}}{\partial x}=-\frac{\partial \beta / \partial x_{\mid \beta=0}}{\partial \beta / \partial \theta}=0
$$

We are now ready to define the political switch line, $\theta^{*}(x ; \lambda)$ :

$$
\theta^{*}(x ; \lambda) \equiv \operatorname{Max}\left\{\theta_{a}(x ; \lambda), \theta_{p}(x ; \lambda)\right\} \quad \text { Political switch line }
$$

It follows that agents of type $\theta \leq \theta^{*}(x ; \lambda)$ demand legal reform (the rule of law), and agents of type $\theta>\theta^{*}(x ; \lambda)$ oppose it. Figure 2 depicts an example of a political switch line.

\subsection{Interaction of economics and politics}

We next show that, if some agents choose to strip assets, then at least some of those agents will oppose the establishment of the rule of law: Economic choices in equilibrium are linked to political choices.

Proposition 3. $\theta_{a}(0 ; \lambda)>\theta_{p}(0 ; \lambda)$ for all $\lambda>0$. 
Proof. Since $\partial \theta_{d} / \partial \lambda>0$ and $\partial \theta_{p} / \partial \lambda<0$ (by Props. 1, 2), this proposition is proved if, as $\lambda$ approaches zero, $\theta_{a}(0 ; \lambda)$ approaches $\theta_{p}(0 ; \lambda)$ from above. So we will show this. Using (1) and (12), $V^{L}=V^{N}(0)=S^{N}\left(0, \theta_{a} ; 0\right)=0$. Using (18), $V^{L}=S^{N}\left(0, \theta_{p} ; 0\right)$. Since $S^{N}($.) is strictly monotonic in $\theta$, it follows that $\theta_{a}(0 ; 0)=\theta_{p}(0 ; 0)$. From Props. 1 and 2 , for any $\lambda>0, \theta_{a}(0 ; \lambda)>\theta_{p}(0 ; \lambda)$. This proves that as $\lambda$ approaches 0 from above, $\theta_{a}(0 ; \lambda)$ approaches $\theta_{p}(0 ; \lambda)$ from above.

Given Proposition 3, there remain two possible cases: either $\theta_{a}()>.\theta_{p}($.$) for all x \in$ $[0,1]$, or there is an interior intersection exists in $\theta-x$ space. In one case, all who build value demand the rule of law and all who strip oppose it. This is more likely the larger is $\lambda$ (which raises $\theta_{a}($.$) and lowers \theta_{p}($.$) ) and the smaller is I^{N}$ (which raises $\theta_{a}($.$) ). In the$ alternative case, $\theta_{a}()=.\theta_{p}($.$) for some value of x$, say $x^{\prime}$. Then if $x>x^{\prime}$, the marginal asset stripper demands the rule of law. This is the scenario that supporters of big bang privatization, who discounted the social consequences of a corrupt privatization and weak corporate governance systems, had in mind. Therefore, this is the interesting case, and Figure 2 depicts it. The intersection of $\theta_{a}($.$) and \theta_{p}($.$) partitions the space (x, \theta)$ into three areas. In Area I, agents build value and demand the rule of law. In Area II, they strip assets and oppose the establishment of the rule of law. In Area III, where $\theta_{a}<\theta_{p}$, they strip assets but demand the rule of law for the sake of the future increase in returns to building value.

\subsection{The stripping ability curve}

To analyze the equilibrium demand for the rule of law, one additional curve is neededthe stripping ability curve -defined as $x=1-H(\theta)$. For each value of $\theta$, the stripping 
ability curve plots on the horizontal axis the fraction of agents $(x)$ whose ability to strip is greater than or equal to that value. If, for example, the ability to strip assets is approximately normally distributed, then the stripping ability curve will have the shape of the dotted line in Figure 3.

\subsection{Equilibrium paths}

An equilibrium path is completely determined by the fraction of agents $x^{*}$ who oppose in each period of state $N$ the establishment of the rule of law. $x^{*}$ solves

$$
x^{*}=1-H\left(\theta^{*}\left(x^{*} ; \lambda\right)\right)
$$

An interior equilibrium occurs as a pair of values $(x, \theta)$ for which the political switch line $\theta^{*}(x ; \lambda)$ and the stripping ability curve, $x(\theta)=1-H(\theta)$, are satisfied. Since both curves are downward sloping, they can obviously have more than one intersection.

Proposition 4. An equilibrium path always exists, but it may not be unique. If there exists an interior value of $x^{*}$ that satisfies $\theta^{*}\left(x^{*} ; \lambda\right)=\theta_{a}\left(x^{*} ; \lambda\right)$ and

$$
-h\left(\theta_{a}\left(x^{*}\right)\right) \frac{d \theta_{a}\left(x^{*} ; \lambda\right)}{d x} \geq 1
$$

then there are at least two other equilibrium values of $x^{*}$, one with a higher and one with a lower probability of transition to the rule of law. On the other hand, if $\theta^{*}(x ; \lambda)=\theta_{p}(x ; \lambda)$ for all $x$, or if at every equilibrium (24) does not hold, then a unique value of $x^{*}$ exists.

Proof. $\phi(x ; \lambda)=1-H\left(\theta^{*}(x ; \lambda)\right)-x$ satisfies $\phi(0 ; \lambda) \geq 0, \phi(x * ; \lambda)=0$, and $\phi(1 ; \lambda) \leq 0$ and is continuous. If, and only if, (24) holds and $\theta^{*}\left(x^{*} ; \lambda\right)=\theta_{a}\left(x^{*} ; \lambda\right)$, then $\phi^{\prime}\left(x^{*} ; \lambda\right)>0$.

(24) has an intuitive interpretation. The inequality holds when the political switch line evaluated at an equilibrium is steeper than the stripping ability curve that cuts it at that point - an example is at $x^{\prime}$ in Figure 3. When this condition holds, the response to a 
perturbation in the opposition to the rule of law (the left-hand side of (24)) is greater than the perturbation itself. So if there is a perturbation above $x$ ', the "switched" agents do not wish to switch back. (The perturbation in aggregate political behavior changes the way agents believe the system will evolve and so changes their economic strategies and political preferences.) If (24) holds for some values of $x$, then that path will be unstable and multiple stable equilibrium paths in state $N$ will exist. Figure 3 depicts the case of two stable values of $x^{*}$ (at 0 and $x^{\prime \prime}$ ).

We next prove that an equilibrium in state $N$ in which all agents demand the rule of law always exists.

Proposition 5. $x^{*}=0$ always exists.

Proof. The proof is by contradiction. So suppose not. Then there exists a type of agent who, when $x=0$, will oppose the rule of law. This means that there will exist a value of $\theta$, say $\hat{\theta}$, that satisfies $\hat{\theta}>\theta^{*}(0 ; \lambda) \geq \theta_{a}(0 ; \lambda)$. The statement $\hat{\theta}>\theta_{a}(0 ; \lambda)$ implies that type $\hat{\theta}$ strips in state $N$, so $V^{N}(0)<S^{N}(0, \hat{\theta} ; \lambda)$. Since $V^{N}(0)=V^{L}($ using $(1))$, the preceding inequality implies $V^{L}<S^{N}(0, \hat{\theta} ; \lambda)$. This contradicts (6), which proves the proposition.

Taken together, Propositions 4 and 5 show that an equilibrium with unanimous support for the rule of law exists, but that it need not be stable or unique. This result is derived under the implicit assumption that all agents know the structure of the economy - in particular, they know that the rule of law is the Pareto efficient regime. We will consider this assumption in the conclusion. 


\section{A numerical example}

In this section we explicitly solve the model for a set of values of the exogenous parameters, ${ }^{15}$ and for the transition probability function $\pi(x)=(1-x)^{2}$. Figure 4 illustrates the partitioning of the space $(x, \theta)$ by the switch lines. Below the economic switch line (Area I), agents build value in state $N$; above it (Areas II and III), they strip assets in state $N$. The economic switch line is downward sloping because increasing opposition to legal reform decreases the expected lifetime return to building value.

The critical value $\theta_{p}(x ; \lambda)$ is a horizontal line that divides Area II from Area III. Above the line, agents' stake in the maintenance of a legal regime that does not interfere with their theft leads them to oppose legal reform. Below the line, that stake is sufficiently small, since the ability to strip is sufficiently small, that agents demand legal reform for the sake of the improvement in the returns to building value.

Area III is of particular interest because the argument was made in Russia in the 1990s that individuals who steal may nonetheless support the establishment of the rule of law. The parameter $\lambda$ - the fraction of current stripping returns reappropriated under the rule of law -influences the size of Area III. If $\lambda$ falls, Area III expands for two reasonssee Figure 5. First, more agents strip assets since the expected return to asset stripping rises (the economic switch line shifts down). Second, fewer asset-strippers oppose legal reform because they forgo a smaller fraction of what they have "stolen" in that period in the transition to the rule of law (the political switch line shifts up).

In the limiting case, $\lambda=0$ : "stolen" assets are fully protected. In this limiting

\footnotetext{
${ }^{15}$ The parameter values are $f=0.05, I^{L}=0.01, I^{N}=0.0475, \tilde{g}=1.05, \tilde{z}=0.9, \lambda=0.3$, and $\delta=0.945$. The excel program is available at www.econ.worldbank.org/staff/khoff.
} 
case, all agents in our model would demand the rule of law-see Figure 6. This result holds generally rather than just in the case of this numerical example. To see this, recall from the proof of Proposition 3 that $\theta_{a}(0 ; 0)=\theta_{p}(0 ; 0)$. Recall also that the assumption in (6) that the rule of law is the Pareto efficient regime fixes a maximum upper bound $\theta_{\max }$ on the distribution of types in the population. It is easy to check that $\theta_{p}(x ; 0)=\theta_{\max }{ }^{16}$, and so all agents demand the rule of law, as was to be shown. But we will argue in Section 4 that in a democracy, $\lambda$ is bounded away from zero. In brief, this is because perceptions of justice constrain the range of possible laws and because, even if the political framework remains unchanged, democracy constrains the range of commitments that a government can make for the future. Given that, $\lambda>0$ and Area II is not the empty set.

To illustrate an equilibrium, we need to specify a distribution of stripping abilities in the population. We consider a very simple distribution: suppose that two-thirds of the population have $\theta=\theta_{\max }$, and for the remaining one-third, $\theta$ has a uniform distribution on $\left[\underline{\theta}, \theta_{\text {max }}\right] .{ }^{17}$ Figure 7 depicts the stripping ability curve as a dotted line and superimposes on it the graphs of $\theta_{a}(x ; \lambda)$ and $\theta_{p}(x ; \lambda)$. There are two stable equilibrium paths in state $N$ : at $x^{*}=0$ and $x^{*}=0.75$.

A striking aspect of the numerical analysis is that the two possible stable outcomes differ markedly in the expected length of the transition. Along the first path, the transition occurs in the period 1. Along the second path, the transition is expected to

\footnotetext{
${ }^{16}$ Evaluated at $\lambda=0, \theta_{p}$ is implicitly defined in (16) by $V^{L}=S^{N}\left(x, \theta_{p} ; 0\right)$ and (since stripping returns are invariant to the state of the world if $\lambda=0),(14)$ simplifies to $S^{N}\left(x, \theta_{p} ; 0\right)=\theta_{p} /[1-z] . \theta_{\max }$ is implicitly defined from (6) by $V^{L}=\theta_{\max } /[1-z]$. It follows from these three equalities that $\theta_{p}=\theta_{\max }$.

${ }^{17}$ In the numerical example, we set $\underline{\theta}=0.66$, but our qualitative results are independent of the choice of $\underline{\theta}$.
} 
occur in period $16 .{ }^{18}$ Figure 8 depicts the growth paths of aggregate expected income associated with the two stable equilibrium values of $x^{*}$, under the assumption that each agent has control rights over an equal share of aggregate assets. ${ }^{19}$ We normalize the initial value of aggregate assets to one. If the vertical axis were measured in logarithms, the initial decline and the expansion paths would be straight lines. Along the lower path, expected income falls as assets are stripped, has a dip when the transition to the rule of law occurs in period 16 because agents lose a fraction $\lambda$ of their stripping returns, and then expands at a constant rate. In this equilibrium, each agent adopts a rational, forward-looking strategy given the political behavior of others, but it is one that collectively the agents would regret: In the example, the present discounted value of expected lifetime income in aggregate is 4.5 along the lower path, compared to $V^{L}=5.5$ along the higher path.

The declining segment of the income curve overstates the growth path of GNP, since part of the income of asset strippers is "theft." The dip in the period of transition to the rule of law is also redistribution, not a real decline. Abstracting from the dip, the actual difference in the growth paths of GNP is greater than the difference in the agents' aggregate income. As the figure illustrates, an economy that experiences a longer period of no rule of law will always be poorer than another economy with the same initial wealth but a less prolonged experience without the rule of law: The economy starting along the

\footnotetext{
18 One can show by standard methods that given a probability of transition $\underline{\pi}$, the expected period of the transition is $1 / \underline{\pi}$. In our example, $x^{*}=0.75, \pi\left(x^{*}\right)=\left(1-x^{*}\right)^{2}=0.0625$, and $1 / \pi\left(x^{*}\right)=16$.

${ }^{19}$ This implies that the fraction of agents who strip assets equals the fraction of assets that are stripped. $\theta_{a}(0.75 ; 0.3)$, which is indicated by a + sign in Figure 7 , is at the $13^{\text {th }}$ percentile of the distribution of stripping abilities. Thus, 13 percent of agents build value, and the rest strip.
} 
lower equilibrium path will never catch up. Our simplifying assumption of constant returns to investment is what leads to this stark result. We will discuss alternative assumptions in Section 4

Besides the potential opposition to the rule of law from those who strip assets, another source of opposition is from those who have access to power that enables them to appropriate great wealth from the state. They do not want equal treatment under the law, a central component of the rule of law. One way to allow for that in our model is to introduce a set of agents who always have a preference for the non-rule-of-law state-i.e. to make a qualitative change in the distribution of $\theta$ that departs from the assumption in (6). Figure 9 depicts a simple parameterization. ${ }^{20}$ The figure shows that the minority of agents for whom stripping dominates building value under the rule of law have a disproportionate influence on the equilibrium, since their opposition to the rule of law lowers the expected relative return to others of building value. ${ }^{21}$ This is what is captured diagrammatically by the downward sloping portion of the political switch line. The presence of this minority eliminates the higher equilibrium path (at $x^{*}=0$ ) and leads to a unique stationary equilibrium path (at $x^{*}=0.85$ ) along which the expected transition to the rule of law occurs very late.

\section{Two policy applications}

In this section, we assess the implications of our model for the sequencing of reforms and for macroeconomic policy.

${ }^{20} 20$ percent of the agents have $\theta=1.2>\theta_{a}(0 ; 0.3)$, and the rest are uniformly distributed on $[0.66,1.2]$.

21 The model is an example of a general class of models where "responders" -agents whose decisions are predicated on aggregate behavior-respond in a manner that reinforces the minority of "non-responders," whose preferences are independent of aggregate behavior; see Haltiwanger and Waldman (1991). 


\subsection{The sequencing of reform}

Our analysis identifies characteristics of an economy that affect how long it is likely to take to reach the rule of law. Decisions made prior to the strategic setting analyzed in our model affect these characteristics. The model provides a way of thinking about the debate over alternative sequences of reform in transition economies: privatization first, institution-building second (henceforth, "big bang"privatization) versus building institutions for corporate governance first and privatizing large state enterprises second (henceforth, "gradualism”).

At the outset of the transition from communism to a market economy, a central issue of debate was whether it was feasible to preserve wealth within the state. Let us assume that the state owns assets that diminish at rate $\mu$ as long as they are owned and controlled by the state. If the government announces that it will begin to privatize state enterprises after $T$ periods, i.e., under gradualism, the cost is the decay of state assets.

We can think of the policy of gradualism as creating corporate governance mechanisms that reduce the ability of an agent of any type to strip assets; such mechanism shift the stripping ability curve left. We parameterize that shift by $\omega$. As Figure 9 showed, in the neighborhood of a stable equilibrium, a shift left in the stripping ability curve reduces the opposition to establishment of the rule of law.

Suppose that policy-makers are solely concerned with the maximization of aggregate expected income, $Y$. We can write the equation $Y^{b}(\omega)=Y^{g}(\mu)$ to define a locus of $(\omega, \mu)$ where policymakers are indifferent between big bang privatization and gradualism-see Figure 10. If $\mu$ is high, then $Y^{g}$ is low and big bang is preferred. If $\omega$ is high, then $Y^{b}$ is low and gradualism is preferred. In general, supporters of big bang 
privatization were focusing on the inability of the state to protect the value of assets held within the public sector, and assuming that competition and private ownership would resolve agency problems and force managers to maximize profits (Boycko, Shleifer, and Vishny 1995, 1996). Still another argument made by supporters of big bang privatization was that market-supporting institutional reform was politically infeasible before privatization, so that there was no practicable alternative to privatization first, followed by institution-building.

Poland provides an example where privatization of large state enterprises was delayed and wealth within the state was preserved ( $\mu$ was low). Given Poland's success in preserving wealth and also in moving towards the rule of law (Grzymala-Busse 2003 and EBRD 2004), there is a strong presumption that big bang privatization would have been inferior to the gradual privatization strategy that Poland adopted. Further, with respect to Russia's principal assets—natural resources_ Russia could plausibly have done a relatively effective job of preserving these assets within the public sector. For example, with respect to oil reserves, one can at worst steal the flow and allocate the productive inputs inefficiently. One cannot, if the right to sell such assets does not exist, steal the capital value. But whether policy of gradualism would have been politically feasible in Russia is clearly contentious.

\subsection{Macroeconomic policy}

The second policy we consider is macroeconomic policy. We will argue that a narrow focus on stabilization can block the transition to the rule of law if it reduces the relative returns to building value. The main point can be illustrated with a very simple example. Suppose that the establishment of the rule of law depends on a majority voting 
rule: $\pi=0$ if $x>1 / 2$ and otherwise $\pi=1$. The "tipping point" at which the rule of law is established is a population fraction $\hat{x}=1 / 2$.

Associated with the tipping point is a critical value of stripping ability, which we denote by $\hat{\theta}$, such that half of the population has a stripping ability above the critical value and half below it. To make things interesting, we assume that $\hat{\theta}$ is sufficiently high that if an individual of type $\hat{\theta}$ strips, then he will have an interest in voting against the establishment of the rule of law in the current period. Formally, $\hat{\theta}>\theta_{p}(. ; \lambda)$. This inequality will be satisfied if $\lambda$ is sufficiently large and $z$ is sufficiently small.

The establishment of the rule of law now depends completely on the incentives of the individual of type $\hat{\theta}$. If he prefers to strip assets rather than build value, then so will at least half the population (those with ability to strip above $\hat{\theta}$ ), and the rule of law will surely not be established. Denote the discounted sum of his lifetime payoffs from stripping assets by $S^{N}(\hat{\theta}, r)$, where the first argument of this function denotes the individual's stripping ability and the second denotes the interest rate.

If, however, he prefers to build value rather than strip, then again so will at least half the population (those with ability to strip less than $\hat{\theta}$ ) and the rule of law will be established with certainty. Denote the discounted sum of lifetime payoffs from building value by $V^{L}(r)$. Thus, as an individual of type $\hat{\theta}$ votes, so votes a majority.

Consider next the decisive voter's lifetime payoffs from alternative actions. If he strips assets in the non-rule-of-law state, $\pi=0$ and his lifetime payoff is $S^{N}(\hat{\theta}, r)=s^{N}(\hat{\theta}, r)+z S^{N}(\hat{\theta}, r)$. If he builds value, then $\pi=1$ and his lifetime 
payoff is $V^{L}(r)=b^{L}(r)+g V^{L}(r)$.

We are now ready to consider the effect of macroeconomic policy. Government chooses a level of public spending $(G)$ and through monetary policy influences the level of the interest rate. Under plausible circumstances, raising $r$ lowers the relative return to building value: at a higher value of $r$, the cost of capital is higher, the likelihood of credit rationing is greater, and future profits obtained from current investments are more heavily discounted. For simplicity, suppose that the level of $G$ does not affect the relative return to building value. (This would be easy to generalize.) Then the rule of law will be established if and only if

$$
\frac{s^{N}(\hat{\theta}, r)}{1-z} \leq \frac{b^{L}(r)}{1-g}
$$

Rule-of-law constraint

Equating the two sides of this inequality defines a critical value of the interest rate, $\hat{r}$. Only if the interest rate is below the critical value will the rule of law be established. We call this the "rule-of-law constraint."

Suppose that social welfare depends on growth, the level of social expenditures, and inflation and, in turn, these three variables depend on $r$ and $G$. Then welfare is an indirect function of these two government policies. So let us write, for state $L$, that function as $\Omega(G, r)$. Figure 11 depicts a possible shape for the iso-welfare curves in state $L$. In the traditional approach, the social optimum is at point $P$, where $\Omega_{r}=0$ and $\Omega_{G}=0$.

Our model poses a fundamental objection to the traditional approach. The structural equations relating growth, social expenditures, and inflation to the policy instruments $\{r, G\}$ depend on the institutional structure, which itself is endogenous. Macroeconomic policies and institutional evolution are not independent issues, especially 
in an economy such as Russia's, which was in the midst of institutional evolution. Yet outside experts advising particular macroeconomic policies virtually never took into account the political and institutional consequences of their macroeconomic policies. ${ }^{22}$

Suppose that social welfare under the rule of law is so much higher than under no rule of law that we need only focus on the rule-of-law state. Then we must recognize that $\{r, G\}$ should be chosen so that the rule of law emerges as part of the political equilibrium. This requires $r \leq \hat{r}$. The iso-welfare curves are dashed in the policy region where the rule of law is unattainable, and maximum social welfare is obtained at point $P^{\prime}$, not $P$.

In this case, defenders of tight monetary policies in Russia who said that the problem was not the policies, but the weak Russian institutions, were missing the mark. If our analysis is correct, the institutions themselves are affected by the macroeconomic policies, and in a way that can be adverse to the creation of the rule of law.

\section{Discussion of the assumptions}

This section examines the assumptions of the model, and discussions extensions and alternate assumptions.

\subsection{Intertemporal effects}

We examine first the assumption that today's political state affects today's economic action, and that today's economic action affects one's "vote" for the political regime that

\footnotetext{
${ }^{22}$ Advisers often emphasized the painfulness of the reforms (implying that they did not believe the benefits would be reaped in the short run), and seemed to hope that the belief that the reforms would be sustained would enhance the political constituency for reform. But they did not seem to contemplate the alternative dynamic that our model suggests: that stringent macroeconomic policy would undermine the political constituency for reform, and therefore that they would worsen even the economic outcomes.
} 
will prevail next period. In the case of perfect "grandfathering," the link would not exist. In the case of perfect capital markets, the link would be greatly attenuated.

Grandfathering. First, if $\lambda$ is set equal to zero in the initial period of the rule of law, then those who have "stolen" assets are fully protected under a change in the legal regime towards rule of law. It follows using (6) that the political interests of all individuals would lie with the establishment of the rule of law (recall Figure 5). However, empirical evidence suggests that perceptions of justice constrain the range of possible laws. This limits the extent to which—under any rule of law—certain actions used by strippers to maximize their returns could be immune from judgment. The perceived justice of a system is important to gaining the cooperation of those involved in the process of producing the rule of law, e.g., judges, regulators, and jurors (Robinson and Darley 1995), obeying the law (Tyler, 1990), and complying with government prescriptions (Levi 1997).

Further, in a democracy, to make a credible commitment to grandfather the existing distribution of property rights would require blocking the emergence of a coalition that seeks better policies if the impact of the initial distribution of property rights is sufficiently adverse. This would require disempowering the population. If it is feasible for a given government to commit not to take back the privatized property, the commitment might lead to an improvement in the security of property rights only in the short run. In that case, those with control rights would make an investment today only to strip more efficiently in the future. Stripping assets may thus dominate building value—even under the rule of law—by those who have obtained their assets illegitimately. We have not modeled a reversion from the rule of law state to the non-rule-of-law state. This, too, can be modeled in a Markovian 
way. The greater the number of those who have obtained their assets illegitimately, the more likely a reversion would be.

In fact, we believe our model underestimates the importance of the link between what happens today and what happens in the future. A commitment to the rule of law today may proscribe not only certain actions used by asset-strippers, but also certain processes by which the assignments of assets were made. This means that the value of an asset under the rule of law depends in part on how the asset was obtained. If it was obtained through a process that is viewed as, or comes to be viewed as, illegitimate, then there is a certain probability that it will be reappropriated by the state, even under the rule of law. ${ }^{23}$

There is still a further difficulty in implementing grandfathering. No matter how finely property rights are specified, there remain areas of ambiguity, and both their scope and how those areas of ambiguity are addressed almost define whether there is a rule of law. A commitment to give asset strippers wide discretion to determine the adjudication of disputes is not a rule of law as that term has come to be used. ${ }^{24}$

Capital markets. Besides a fall in $\lambda$, the other possibility that would attenuate intertemporal effects in our model is that the prospect of the rule of law in the future always induces individuals to take actions today to maximize the long-run value of their assets. This might be the case, for instance, if there were perfect capital markets (with non-governmental enforcement). With perfect capital markets and the future prospect of

\footnotetext{
23 As Przeworski (1991, p. 64) emphasizes, "in a democracy, substantive commitments cannot be binding": each government is sovereign and can affect only the transaction costs of a change in the law.

${ }^{24}$ Feudal lords had well-defined property rights (extending well beyond what we today call ordinary property into rights over vassals and serfs), but disputes over property rights were not guided by predictable rules: the feudal lord had wide discretion. Such a legal regime does not provide the security of property rights required by a market economy.
} 
the establishment of the rule of law, it would be in the interest of each individual to take actions that maximize the value of assets because he could "capture" that value. This may have been the economic model in the minds of the supporters of big bang privatization, but the whole issue of transition concerns the sequencing and pacing of reforms and institution creation. Privatization occurred prior to the creation of effective capital markets. ${ }^{25}$

Ironically, with imperfect capital markets, the belief that the rule of law might eventually be established might lead to even more, and more inefficient, asset stripping than our simplified model—with a fixed intensity of stripping—suggests. Stripping assets sufficiently quickly ensures that assets appropriated illegitimately from the state would not be reappropriated. The historian Orlando Figes (1996) describes how, in a Russian town on the weekend between the departure of the White Army and the arrival of the Red Army in 1920, citizens stripped the streets of the trees. In Brazil, the announcement that restrictions were about to be imposed to prevent environmentally unsound logging may have exacerbated such unsound logging in the short run. In Russia, those controlling assets, especially with uncertain long-term rights, had an incentive to strip assets quickly, before they either lost those rights or before controls (such as those associated with the export of capital) were imposed. ${ }^{26}$

\footnotetext{
${ }^{25}$ Further, if $\lambda \neq 0$, then even with perfect capital markets, outcomes would not be fully efficient, because some of the agents' efforts would be directed to redefining the share $\lambda$ of stripping returns that the government would reappropriate. For simplicity, we have assumed $\lambda$ to be fixed.

${ }^{26}$ In that sense, the belief that the rule of law would be introduced not immediately, but in the intermediate term, represents the worst of all possible worlds. If it were believed that the rule of law would be introduced only in the very long run, a more efficient pattern of asset stripping could emerge. If it were believed that the rule of law would be introduced very quickly, then it might not pay to strip assets, given
} 
Part of the hoped-for dynamics of the transition was that the more assets that the state privatized, the greater the assets whose value would be increased by the rule of law, and so the greater the political pressures from the property owners for legal reforms. But if individuals have an alternative location for the investment of their wealth, then the constituency for the rule of law will be diminished for two reasons. First, they do not need the rule of law to obtain the higher returns to building value. Second, because others are taking their assets out of the country, the economy is in recession, which reduces the returns to investing in the country under any legal regime. The policies pursued in the transition created a world with safe havens protected by the rule of law, and also places where individuals could use their control rights to steal. That is why international capital controls play a key role in shaping the political pressures for the rule of law.

\subsection{Stationarity in state $N$}

We next examine the assumptions of the model that give rise to an equilibrium in which, as long as the non-rule-of-law state prevails, the fraction of people opposed to reform is constant: $x_{t}=x_{t+1}=x_{t+2}=\ldots$. Our qualitative results would continue to hold for any

the high value of assets under the rule of law. Thus, what happened in Russia may have represented the worst of all possible worlds. Individuals who believed that the rule of law would eventually be established worried that in that case, their illegitimately obtained property rights would be questioned, as indeed they were; and the way to most surely secure those property rights was to strip the assets and move them outside the jurisdiction. Some outsiders recognized this problem and argued strongly to let bygones be bygones, to create an oligarch-dominated society that would ensure that the oligarchs felt secure in their property rights, so that they might even repatriate funds they had previously taken out. But this strategy too was risky, for it meant a long-term commitment to a framework that we have identified as a non-rule-of-law state (in which oligarchs receive preferential treatment), which in turn encourages asset stripping by others and, of course, slows the movement towards the rule of law (see, e.g., Holmes 2003). 
equilibrium process in which higher opposition to the rule of law today $\left(x_{t}\right)$ was associated with beliefs that $x_{t+1}$ would be higher. Then a higher $x_{t}$ would always be associated with higher asset stripping.

For simplicity, the model assumes that each individual is characterized by a timeinvariant ability to strip. We could assume, without changing the qualitative results of the model, that a type is characterized by a path - a sequence of $\theta^{\prime}$ 's - provided that those types can be ranked so that there are unambiguously lower and higher abilities to strip among agents. Then, as in our model, we could consider the effect on the demand for the rule of law of exogenous changes that shift the distribution of types. Given the variation over time in the distribution of $\theta$, the fraction of agents supporting the non-rule-of-law regime would also vary over time.

We could also consider endogenous shifts in the distribution of types. If stripping assets and building value were characterized by learning-by-doing, then behavior would be self-reinforcing. The model would have the feature that an individual who stripped assets could shift, over time, from a supporter to an opponent of the establishment of the rule of law. (More generally, although (6) once held for all agents, if the non-rule-of-law state persisted sufficiently long, then (6) would cease to hold.). In this case, support for the rule of law would fall over time. As Holmes (2003, pp. 20-21) states,

Bullies and plunderers-who could never flourish if the rules of the game were crystal clear and reliably enforced-cannot be expected to promote or enforce a system that will radically devalue the rude skills of acquisition and domination they have perfected in the state of nature.

The result among different societies, some with initially high and some with initially low levels of asset stripping, could be a bimodal pattern in the constituency for the rule of law, as suggested by the paths of institutional change depicted in Figure 1. 
Deindustrailization, which progressed in Russia in the $1990 \mathrm{~s},{ }^{27}$ is a second factor that might endogenously shift the distribution of abilities to strip. Given Russia's vast natural resources, in ten years Russia will still be a major exporter of natural resources. A bad situation—characterized by a high relative return to stripping—could worsen because the value of man-made capital (machines, buildings, equipment) tends to deteriorate more quickly than that of natural resources under a stripping/low-maintenance strategy. This process may shift the distribution of types, among those who still control assets, toward those with greater ability to strip. In that case, the incentives to strip would be increasing over time and the prognosis for the rule of law would be worse than our model might suggest. ${ }^{28}$

But there are plausible factors that would hasten the transition to the rule of law. The model assumes only two possible activities: building value and stripping assets. If, in addition, there is a subsistence activity ("gardening") that agents could undertake in the nonrule-of-law state, ${ }^{29}$ then ultimately that activity would be adopted by everyone as the asset base was depleted. In the long run, no one would oppose a transition to the rule of law.

For simplicity, the model assumes constant returns to scale to investment. If, as in

\footnotetext{
${ }^{27}$ The value of fuel and mineral exports as a fraction of total exports in Russia rose from 53.2 to 60.6 percent between 1996 and 2000, as the value of exports in manufacturing fell and the value of natural resource exports rose (World Bank, Statistical Information and Management Analysis).

${ }^{28}$ Arguing slightly in the other direction is that the extractive industries still need to finance the investments required for resource depletion, so that there is a need for a minimal rule of law to elicit these funds.

${ }^{29}$ It has to be assumed, moreover, that individuals cannot simultaneously "strip" and engage in this standalone activity, or at least that the increase in value from the rule of law in the stand-alone activity exceeds the decrement in value in the asset stripping activity.
} 
standard growth models, we made the assumption of increasing marginal returns, then as more and more funds were taken out of the economy, the capital stock would become depleted and the attractiveness of reinvesting profits (and of foreign direct investment) and, thus, of the rule of law, would increase.

Another assumption of the model is that beliefs are independent of events that occur after privatization. But the experience of the transition may reinforce one or another view of man; one can learn not to trust. The experience of low or high levels of corruption can guide expectations with respect to the equilibrium that will be achieved. ${ }^{30}$

Further, populations that experience different levels of corruption over long periods may exhibit different behavior because the level of corruption affects the way that behavior is evaluated and, thus, the extent to which societal norms are a discipline device (Dyck and Zingales 2002). Eventually, abuse of power may come to be perceived as legitimate by significant sectors of the society. The response of a Russian minister to allegations of corruption is a case in point: ${ }^{31}$

Vladimir Rushaylo has flatly denied the allegations that 70 per cent of all Russian officials are corrupted ... "Only those who have links with the organized criminal

${ }^{30}$ Experimental economics has addressed the question of what happens when large groups of individuals repeatedly play a coordination game with multiple equilibria. van Huyck et al. (1990) find in laboratory settings that in large anonymous groups, trust is fragile: Once betrayed, it is not restored.

${ }^{31}$ There are two strands of thought suggesting that one should be unconcerned with corruption. One is the principal subject of this paper: that it matters little how property rights are established, only that they be established. The other likens corruption to an auction. With robust competition, the assets are "sold" to the highest bidder. In this perspective, bribe-taking improves economic efficiency. The only conditions under which such a conclusion might hold would be those in which markets worked well, e.g. because there was perfect information, in which case the issue of corruption itself would simply not arise. Theoretical and empirical work finds that a corrupt state creates regulations so that it can release firms from them in exchange for bribes (Kaufmann and Wei 1999 and Laffont and Martrimort 1999), and finds a negative relationship between corruption and investment, and between corruption and growth (Mauro 1995). 
gangs can be regarded as corrupted officials. Do not mistake bribe-taking for corruption," the Russian Interior Minister stressed.

(RIA news agency, Moscow, March 13, 2001/BBC Monitoring (c) BBC)

Our model overdraws the ability of people to start fresh. After a prolonged period with high asset stripping, it becomes more difficult to implement the rule of law- $\pi(\mathrm{x})$ shifts down ${ }^{32}$.

In limiting cases, e.g. Russia, where high levels of criminal activity were undertaken to obtain control rights, there may be still another reason why it is difficult to exit the non-rule-of-law state. For individuals who engaged in criminal activity, the switch to the rule of law may not entail an increase in the net returns that they can earn from investment because of the risk of retroactive criminal prosecution. Recognizing the huge cost associated with the transition to the rule of law, these individuals may "invest" a great deal in the maintenance of no rule of law, including killing those who work to establish the rule of law. Not only are some individuals locked in by their pasts, but others who might wish to support the rule of law may incur tremendous risks in doing so. ${ }^{33}$ History matters.

\section{Concluding remarks}

There is a logic to the link between private opportunities for wealth creation and institutional change. As Adam Smith (1776, Book III,.iv) argued, the creation at the end of the feudal period of opportunities to invest beyond one's own estate engendered a new

\footnotetext{
${ }^{32}$ And thus, support for the rule of law will (weakly) fall-a proof is in the working paper version of this paper.

33 The assassination in August 2002 of V. Golovlyov, a member of the Duma, is one of a long list of assassinations, nearly all unsolved, of Russian public officials who had links with criminal activities. It is reported that "Mr. Golovlyov was killed by former cronies because he had jumped [from a criminal past] to the side of the law helping the investigators." (Michael Wines, "Politics in Moscow More Dagger than Cloak," New York Times, August 24, 2002, pp. A1-4.)
} 
set of political interests that brought about a slow improvement in institutions. At the end of communism in the former Soviet bloc, the states owned assets of immense value that had been created in some cases by collective efforts over a period of 70 years. The privatization of state enterprises increased private opportunities for wealth creation, but also_-given the absence of effective corporate governance systems—for theft. We showed that even when all agents are better off building value in the rule of law state than stripping assets in a lawless environment, once agents have engaged in asset stripping, at least some of them will have in an interest in prolonging a weak, corrupt state that does not interfere with their theft. Thus, the path of institutional change can be inefficient even from the narrow point of view of the asset strippers, who do not internalize the effect of their economic choices on how the political environment evolves.

A central criticism of privatization of large enterprises, but not of smaller privatizations, is that it led to the creation of large agglomerations of wealth. We have presented a model of why privatization that does not create concentrated wealth might fail to induce a demand for the rule of law. The argument for why oligarchic privatization might fail to do so is even more compelling.

We have focused on the problem of the transition of post-communist states to a private ownership economy with the rule of law. But the issues raised here bear on a question of concern in many post-colonial developing countries, as well: How does a society with a distribution of property rights whose legitimacy is contested, establish a foundation for building the rule of law? The problem of legitimacy is inherent in the problem addressed in this paper because the assignment of property rights prior to the creation of the rule of law—or of a government with political legitimacy—will itself not 
have legitimacy and therefore not be secure. ${ }^{34}$ This question has bedeviled many countries where a legacy of colonial rule is a set of weak and conflicting property rights institutions and patterns of authority. To cite just one example, when land-hungry citizens in Zimbabwe seized control of large, privately owned, commercial farms in 2000

"the courts and the international media [interpreted this] as a battle over 'the rule of law,' but the crisis quickly expanded to a debate over the history of racial domination and the legitimacy of inherited laws and institutions... Responding to international pressure that land reform must proceed within the law, Zimbabwean activists and intellectuals replied that [the distribution of property rights ] was an artifact of colonial rule... Today, they point out, it is illegal in Zimbabwe to possess stolen property. So who is subverting the rule of law?" (Berry, 2002, p. 36, 40).

A view going back to Ronald Coase is that economic efficiency requires only unambiguously defined property rights. The Coasian view implies that it would be best — on efficiency grounds — to grandfather the existing distribution of property, no matter how obtained. We have argued that there are three difficulties with the Coasian line of reasoning. One difficulty is the incompleteness of any commitments made to grandfather the existing distribution: no matter how finely property rights are specified, there remain areas of ambiguity. Every society circumscribes in some ways the use of property rights. Another difficulty is obtaining cooperation from judges and jurors and citizens in implementing a set of rules that are perceived as unwarranted or unjust. But the most fundamental difficulty concerns the credibility of a commitment to grandfather the existing distribution of property rights. If it is ultimately the social consensus about

\footnotetext{
34 This paper has focused on how the lack of legitimacy of property rights affects the dynamics of the creation of the rule of law. A full discussion of the subject of the title of this paper would include an account of the characteristics of the rule of law that generate legitimacy of property rights. On this, see, e.g., Unger (1976) and Dahl (1990).
} 
the fairness of the distribution that underlies the security of such rights, then in order to establish the rule of law after a period of widespread asset "theft," either the distribution must change or beliefs about the fairness of the distribution must change. Myths have a role to play in building a political consensus, ${ }^{35}$ but inventing myths takes time.

It is at times of transition that new myths and new beliefs are created. At the beginning of the transition, not everyone believed that privatization and the creation of a market economy would, at least by themselves, lead to an improvement in the well-being of most citizens. Support for the Coasian position depends on the fact that it leads to efficient outcomes. There is an equilibrium in which this is not believed, and justifiably so, because it does not produce the promised results if it is not believed. (Our paper has focused on this type of coordination failure.) Worse still, in the real world, individuals do not know the structure of the economy. They do not know for sure that a political and economic system with privatization and the rule of law will lead to Pareto efficiency and most likely make them better off. They are Bayesians. They update their beliefs about the accuracy of official statements that privatization will lead to efficiency both on the basis of their short-run observations of economic outcomes, and on the basis of the incentives of those taking particular positions. The fact that short-run outcomes were so poor, and that the wealth gains of those advocating privatization were so large, created further doubts about the validity of the Coasian view. This inevitably led to political and

\footnotetext{
${ }^{35}$ Some have suggested that the leading business owners in Russia are like the U.S. robber barons who made fortunes from predatory behavior in the $19^{\text {th }}$ century, yet whose wealth ultimately came to be viewed as legitimate. But the robber barons established new industries that gave rise to broadly distributed economic benefits-achievements that made them cultural heroes. By contrast, beneficiaries of a corrupt privatization owe much of their wealth to the transfer of pre-existing state enterprises. In Russia, the privatization has not so far delivered the promised broadly distributed economic improvement.
} 
economic behaviors making adverse outcomes more likely than our analysis of equilibrium paths would suggest. A full analysis of the Bayesian dynamics, ${ }^{36}$ while beyond the scope of this paper, would almost surely be even more pessimistic for the success of the rapid privatization strategy.

The presumption of supporters of big bang privatization was that the faster state property was turned over to private hands, the faster a true market economy, including the rule of law, would be established: effective political pressure for legal reform would appear only after privatization. In our model, although privatization does automatically create some agents demanding the rule of law, it may also create agents whose entrepreneurial efforts are directed towards theft and who oppose legal reform. Our analysis shows that even if eventually the rule of law is established—and there is no assurance that it will be — big bang privatization may put into play forces that delay the establishment of the rule of law. The tortoise once again may beat the hare! What has happened in Russia and other economies in transition in the last fifteen years suggests that this is more than a theoretical possibility.

\footnotetext{
${ }^{36}$ In which agents update their beliefs both about the state of the economy and about the truth of the Coasian view.
} 


\section{Appendix}

We prove the following property of the economic switch line:

Lemma. $[g-z] V^{L}-g \bar{s}\left(x, \theta_{a} ; \lambda\right)+z \bar{b}(x) \geq 0$

Proof. Rearranging terms in (10) and using (12) gives

$\left(10^{\prime}\right)[g-z] V^{L}=\frac{\bar{s}\left(x, \theta_{a} ; \lambda\right)-\bar{b}(x)-[1-\pi]\left[g \bar{s}\left(x, \theta_{a} ; \lambda\right)-z \bar{b}(x)\right]}{\pi(x)}$.

The lemma is equivalent to

$$
[g-z] V^{L}-g \bar{s}\left(x, \theta_{a} ; \lambda\right)+z \bar{b}(x)=\frac{1}{\pi}[1-g][1-z]\left[\frac{\bar{s}\left(x, \theta_{a} ; \lambda\right)}{1-z}-\frac{\bar{b}(x)}{1-g}\right]
$$

(by substituting for $[g-z] V^{L}$ from $\left(10^{\prime}\right)$ and rearranging terms)

$$
=[g-z]\left[V^{L}-V^{N}(x)\right]
$$

(by substituting for $\bar{b} / 1-g$ from (13) and $\bar{s} / 1-z$ from (14) and

recognizing that $\left.V^{N}(x) \equiv S^{N}\left(x, \theta_{a} ; \lambda\right)\right)$.

Since $g>z$ and $V^{L} \geq V^{N}(x)$, the lemma is proved. 


\section{References}

Acemoglu, D. (1995). 'Reward Structures and the Allocation of Talent', European Economic Review, vol. 39, pp. 17-33.

Aslund, A. and Dmitriev, M. (1999). 'Economic Reform vs. Rent Seeking', in (A. Aslund and M. Olcott, eds.), Russia after Communism, Washington, DC: Carnegie Endowment for International Peace.

Berry, S. (2002). 'Debating the Land Question in Africa', Comparative Studies in Society and History, vol. 44:4 , pp. 638-68.

Black, B., Kraakman, R. and Tarassova, A. (2000). 'Russian Privatization and Corporate Governance: What Went Wrong?', Stanford Law Review, 52, pp. 1731-1801.

Boycko, M., Shleifer, A. and Vishny, R. (1995), Privatizing Russia. Cambridge, MA: MIT Press.

Boycko, M., Shleifer, A. and Vishny, R. (1996), 'A Theory of Privatization', Economic Journal 106 (435), pp. 309-319.

Dahl, R. A. (1990), After the Revolution? Authority in a Good Society. New Haven: Yale University Press (revised edition).

Dyck, A. and Zingales, L. (2002). 'The corporate governance role of the media', in The Right to Tell: The Role of Mass Media in Economic Development, Washington DC: WBI Development Studies, pp. 107-37.

European Bank for Reconstruction and Development (EBRD) (2004). Transition Report 2004, London: EBRD.

Figes, O. (1996), A People's Tragedy: The Russian Revolution. New York: Penguin.

Freeland, C. (2000), Sale of the Century: Russia's Wild Ride from Communism to Capitalism. New York: Random House.

Graham, T. (2002), 'Fragmentation of Russia', Russia after the Fall (A.C. Kuchins, ed.), Russia after the Fall, Washington, D.C.: Carnegie Endowment for International Peace, 39-61.

Grzymala-Busse, A. (2003). 'Political competition and the politicization of the state in East Central Europe', Comparative Political Studies, vol. 36(10), pp. 1123-1147.

Haltiwanger, J.and Waldman, M.. (1991). 'Responders versus Non-Responders: A New Perspective on Heterogeneity', Economic Journal, vol. 101, pp. 1085-1102. 
Hay, J.R., Shleifer, A. and Vishny, R.W. (1996). 'Toward a Theory of Legal Reform', European Economic Review, vol. 49, pp. 559-567.

Hellman, J. (1998). 'Winners Take All - The Politics of Partial Reform in Postcommunist Transitions', World Politics, vol. 50, pp. 203-234.

Hellman, J. (2002). 'Russia's Transition to a Market Economy: A Permanent Redistribution?', in (A.C. Kuchins, ed.), Russia after the Fall, Washington, D.C.: Carnegie Endowment for International Peace.

Hoff, K. and Stiglitz, J. (2004). 'After the Big Bang: Obstacles to the Emergence of the Rule of Law in Post-Communist Societies', American Economic Review, vol. 94 (3), pp. 753-763.

Holmes, S. (2002). 'Simulations of Power in Putin's Russia', in (A.C. Kuchins, ed.), Russia after the Fall, Washington, D.C.: Carnegie Endowment for International Peace, 7989.

Holmes, S. (2003). 'Lineages of the Rule of Law', in (J.M. Maravall and A. Przeworski, eds.), Democracy and the Rule of Law, Cambridge, UK: Cambridge University Press.

Johnson, S., Kaufmann, D. and Shleifer, A. (1997). 'The Unofficial Economy in Transition', Brookings Papers on Economic Activity, vol. 0(2), pp. 159-221.

Kaufmann, D., Kraay, A. and Mastruzzi, M. (2005). 'Governance Matters IV: Governance Indicators for 1996-2004', World Bank Policy Research Working Paper 3630, June. www.worldbank.org/wbi/governance/govdata/.

Kaufmann, D. and Wei, S. (1999). 'Does "Grease Money" Speed Up the Wheels of Commerce?', NBER Working Paper No. 7093.

Kolodko, G.W. (2000), From Shock to Therapy: The Political Economy of Postsocialist Transformation, Oxford, UK: Oxford University Press.

Laffont, J. and Martimort, D. (1999). 'Separation of Regulators against Collusive Behavior', RAND Journal of Economics, vol. 30(2), pp. 232-62.

Levi, M. (1997), Consent, Dissent and Patriotism, New York: Cambridge University Press.

Marx, K, and Engels, F. [1848] (1998), The Communist Manifesto, New York: Mass Market Paperback.

Mauro, P. (1995). 'Corruption and Growth', Quarterly Journal of Economics, vol. 110 (3), pp. 681-712. 
Murphy, K., Schleifer, A. and Vishny, R. (1993). 'Why Is Rent-Seeking So Costly to Growth?', American Economic Review, vol. 83, pp. 409-14.

Nagy, P.M. (2000), The Meltdown of the Russian State, Northhampton, Ma: Edward Elgar.

North, D.C. (1981), Structure and Change in Economic History, New York: W. W. Norton and Company.

Pistor, K. (1999). 'Supply and Demand for Law in Russia', East European Constitutional Review, pp. 105-108.

Przeworski, A., 1991. Democracy and the Market: Political and Economic Reforms in Eastern Europe and Latin America, Cambridge UK: Cambridge University Press.

Robinson, P. and Darley, J. (1995), Justice, Liability, and Blame: Community Views and the Criminal Law, Boulder, CO: Westview Press.

Roland, G. and Verdier, T. (1999). 'Law Enforcement and Transition', Working Paper 22, CERGE-EI.

Rose, R. (1993). 'Contradictions between micro- and macro-economic goals in postcommunist societies', Europe-Asia Studies, vol. 45 (3), pp. 419-444.

Shleifer, A. and Vishny, R. (1998), The Grabbing Hand - Government Pathologies and their Cures, Cambridge, MA: Harvard University Press.

Smith, A. [1776] (1999), The Wealth of Nations, London: Penguin Classics.

Sperling, V. (200). 'Building the Russian State: Institutional Crisis and the Quest for Democratic Governance', Boulder, CO: Westview Press.

Tyler, T. (1990), Why People Obey the Law, New Haven: Yale University Press.

Unger, R. M. (1976). Law in Modern Society: Toward a Criticism of Social Theory, New York: Free Press.

van Huyck, J.B., Battalio, R.C. and Beil, R.O. (1990). 'Tacit Coordination Games, Strategic Uncertainty, and Coordination Failure', American Economic Review vol. 80(1), 234-48.

Weingast, B. (1997). 'The Political Foundations of Democracy and the Rule of Law', American Political Science Review, vol. 91, pp. 245-63. 

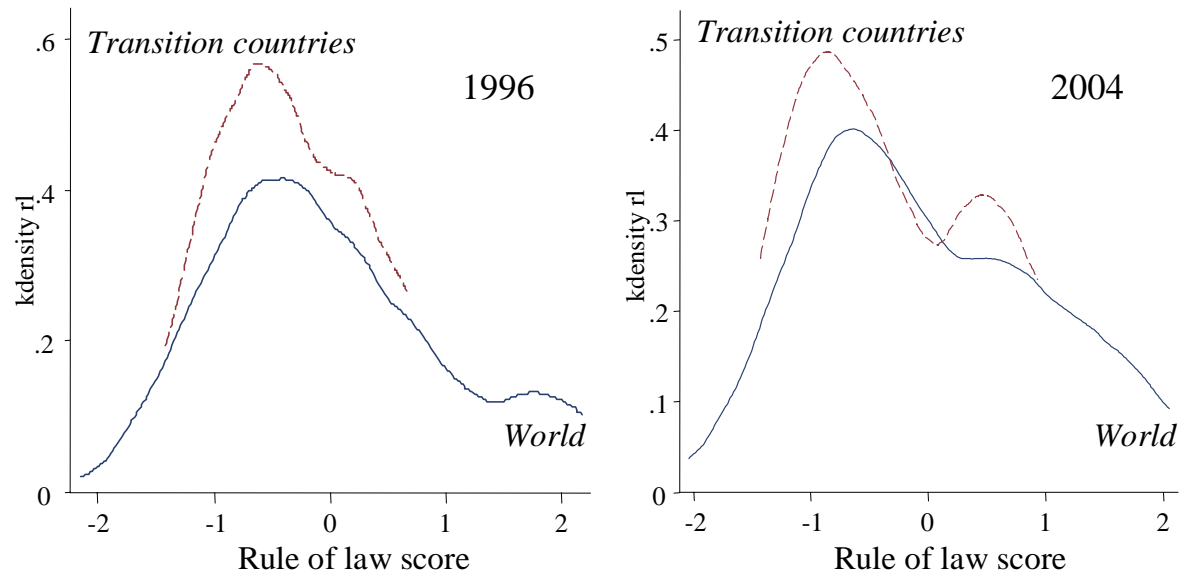

Fig. 1. Distribution of transition countries, and all countries, by their World Bank rule of law scores, 1996 and 2004

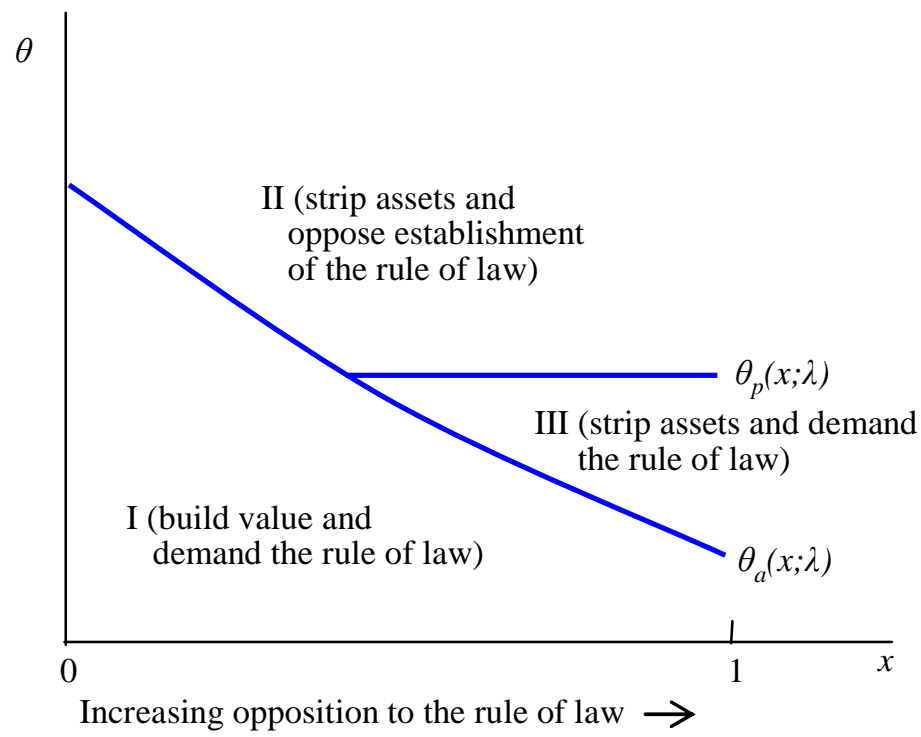

Fig. 2. The switch lines in the non-rule-of-law state 


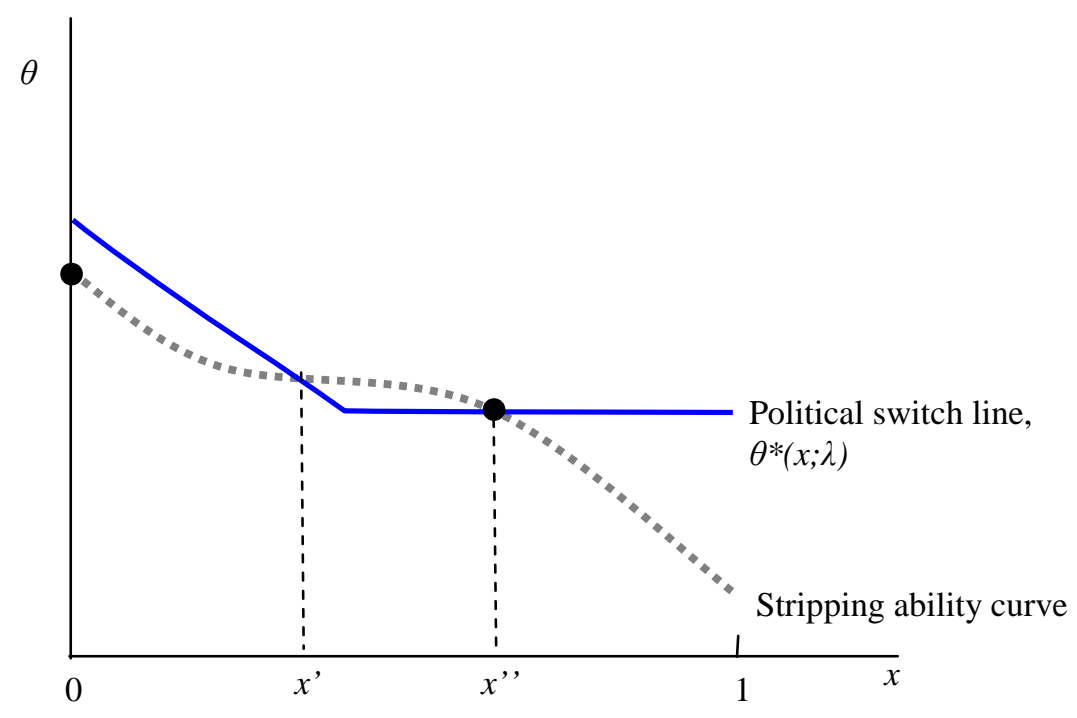

Fig. 3. Multiple equilibria in the non-rule-of-law state

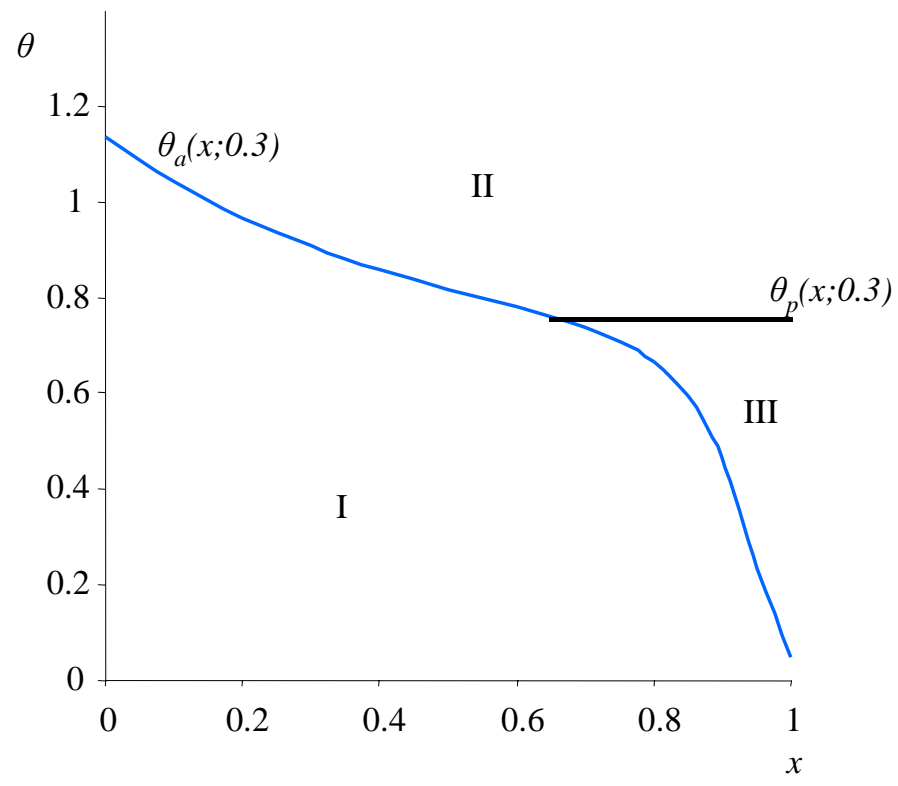

Fig. 4. Numerical example of the switch lines 


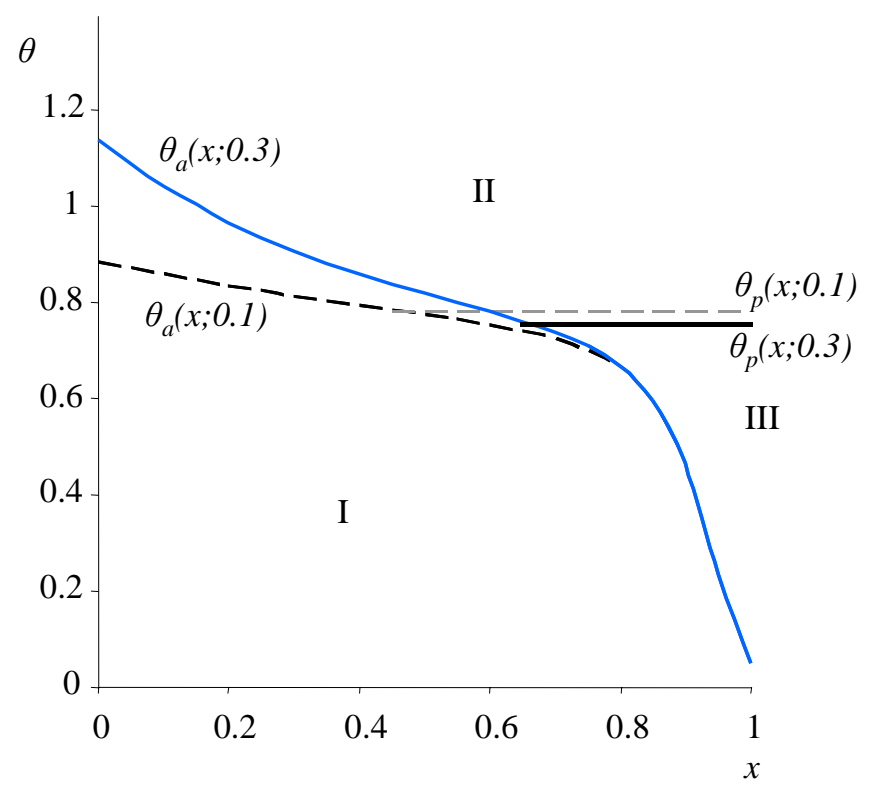

Fig. 5. The effect on the switch lines of a fall in $\lambda$

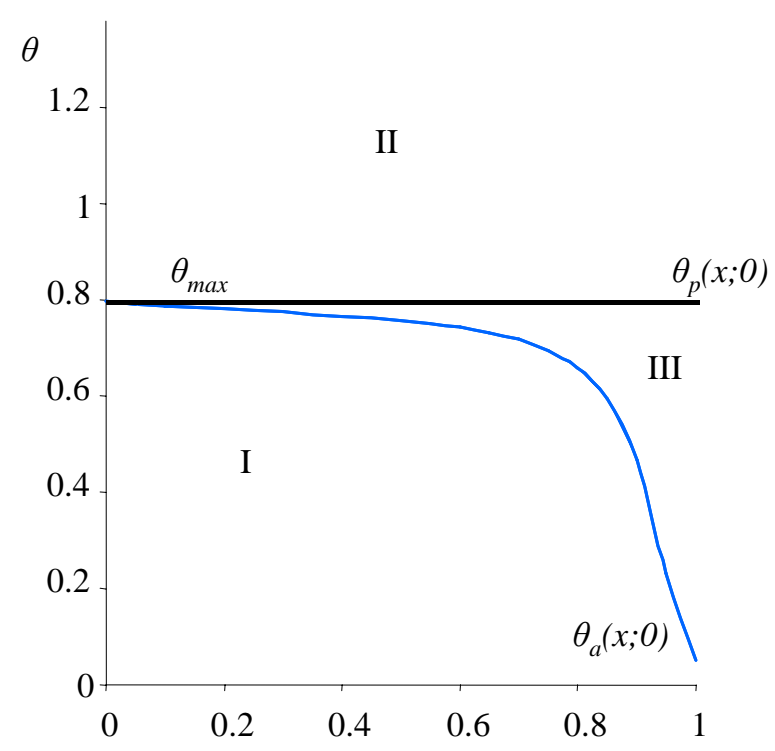

Fig. 6. The switch lines evaluated at $\lambda=0$ (no reappropriation of stripping returns) 


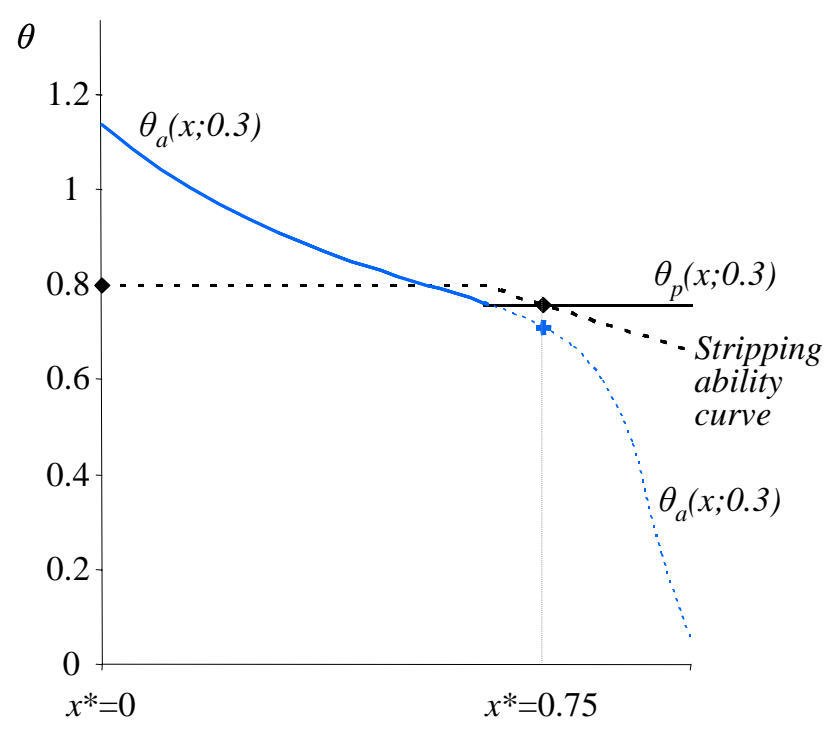

Fig. 7. Numerical example of multiple equilibria in the non-rule-of-law state

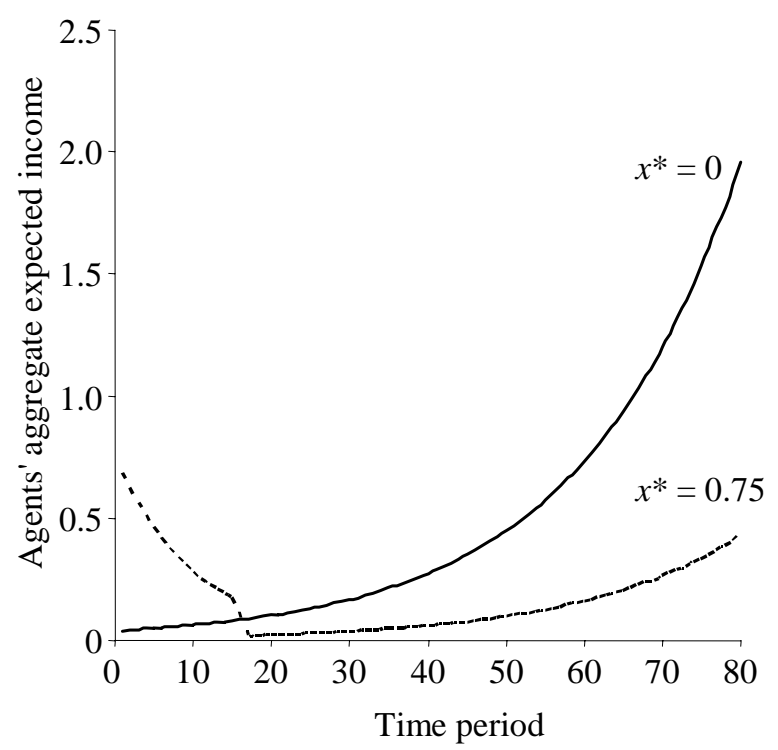

Fig. 8. Stable, equilibrium paths of aggregate expected income 


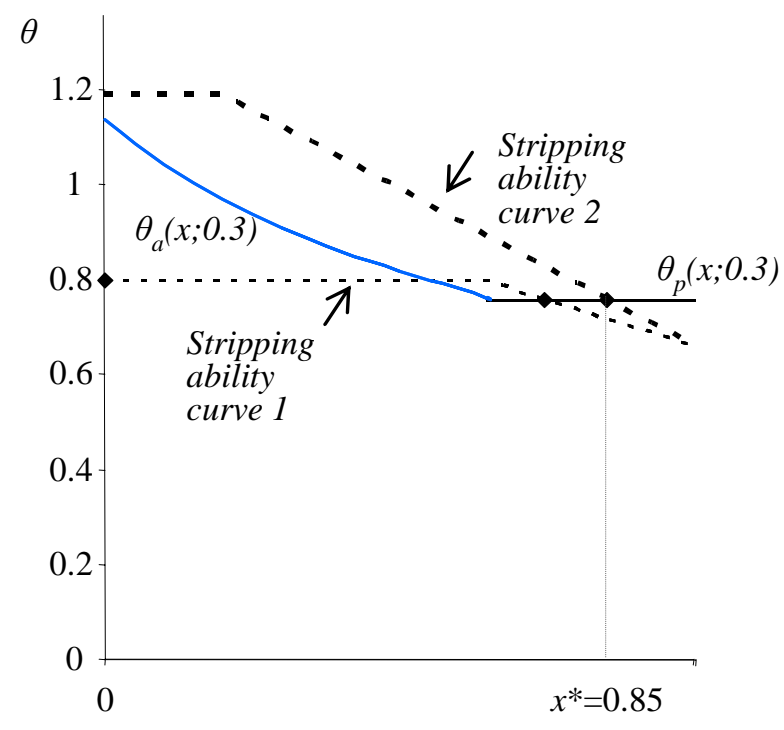

Fig. 9. The effect on equilibrium in the non-rule-of-law state of a shift in the stripping ability curve

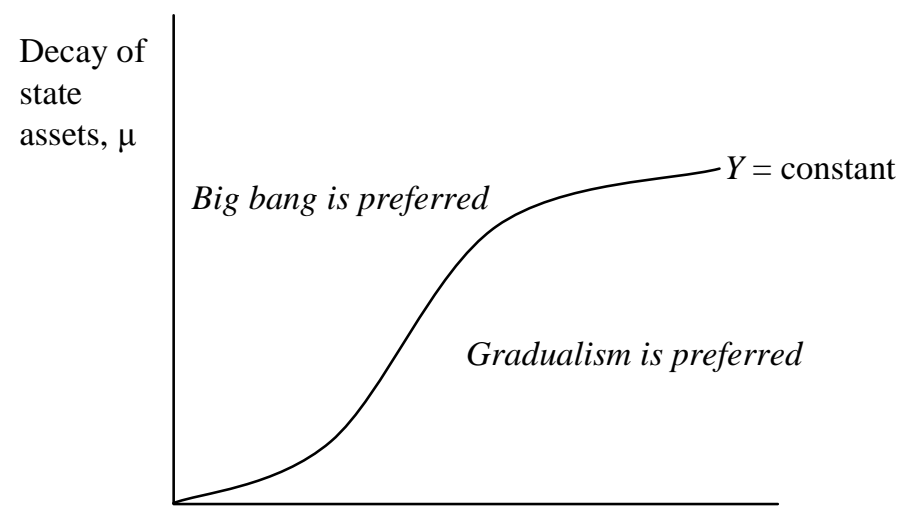

Leftward shift in stripping ability curve, $\omega$

Fig. 10. Trade-offs in the choice of reform sequences 


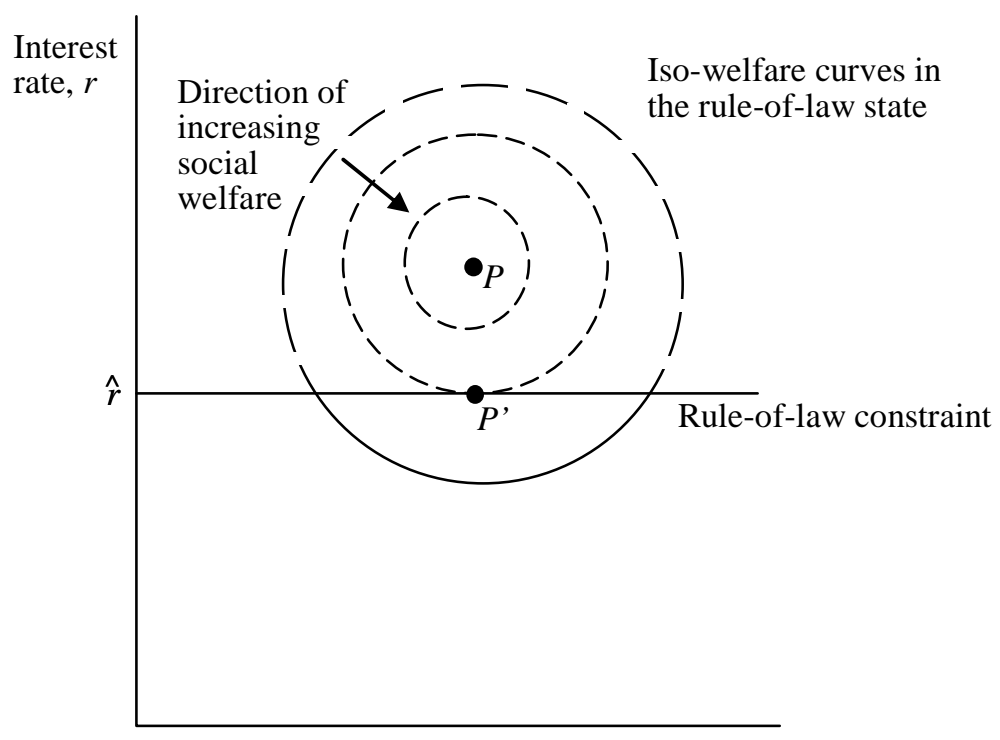

Government spending, $G$

Fig. 11. Rule-of-law constraint on macroeconomic policy 